\title{
Microsurgical Reconstruction of the Oral Cavity and Oropharynx After Cancer Ablation
}

\author{
Mônica Lúcia Rodrigues, Hugo Fontan Köhler and Luiz Paulo Kowalski \\ Department of Head and Neck Surgery and Otolaryngology, A. C. Camargo Hospital \\ Brazil
}

\section{Introduction}

\subsection{A brief history of head and neck reconstruction}

Head and neck cancer treatment may cause significant functional and esthetic morbidity with quality-of-life limiting sequelae. Factors like lesion's topography and extension as well as the function of the compromised structures will determine the characteristics of the defect; the reconstruction modality chosen, the multidisciplinary rehabilitation work and the patient's adaptation capacity will determine the impact of oral cancer treatment on overall life quality. Therefore, it's necessary to perform a critical appraisal of the available methods for reconstruction and its interaction with rehabilitation on each patient in order to ensure optimal results (Gal \& Futran, 2002).

Pedicled fasciocutaneous flaps from the trunk were the major form of head and neck reconstruction until 1963 (Pagedar \& Gilbert, 2009). These flaps have significant limitations due to unreliable perfusion, limited skin island flap, absence of muscle or bone and the need for at least two operations.They were followed by local flaps, with a defined vascular pedicle and a greater extension of available tissue for transfer. They allowed for better functional and cosmetic outcomes and the realization of a wider range of surgeries. Among these flaps we may cite McGregor (McGregor, 1963) and Bakamjian (Bakamjian, 1965) flaps which were the major form of reconstruction after head and neck ablative surgery in the period from 1963 to the end of the seventies.

A major development in head and neck reconstruction was the introduction of the pectoralis major flap by Ariyan (Ariyan, 1979a, 1979b). The pectoralis major flap presented major advantages over the local and random flaps such as: blood supply from a well-defined and calibrous vascular pedicle; the possibility to include skin, muscle and bone in a single flap; long pedicle, allowing for coverage of distant sites like the maxillary sinus and parietal area; primary closure of the donor area; and adequate coverage of the neck vessels after neck dissection.

The development of microvascular surgery parallels that of pedicled flaps with the description by Seidenberg of autologous jejunal transplantation for esophageal reconstruction (Seidenberg, 1959). But the initial large series of microsurgical flaps were not published until the 1970's (O'Brien et al, 1974). Since then, free flaps have become the 
workhorse of head and neck reconstruction with and expanding role and a significant impact on treatment outcome.

\subsection{Advantages of free flaps over pedicled flaps}

We believe that free flaps possess major advantages over pedicled flaps, allowing for better reconstructions and, therefore, a better rehabilitation. The successful reconstruction allows for improved dental and prosthetic rehabilitation with a significant impact on the patient's quality of life.

A major difference between free and pedicled flaps is the available donor areas. While pedicled flaps are restricted to the transplantation of nearby tissues of the ablation site, such limitation is not significant for free flaps, with more than twenty different donor areas already described. It allows for considerations on the cosmetic of the donor area to be evaluated and considered as part of the decision process. A critical example of this advantage is the possibility of sparing thoracic scars and breast deformity in young female patients.

Free flaps also allow for tailor-made reconstructions with the use of flaps that are ideally suited to that specific region and defect. Factors like tissue malleability, thickness and hair coverage may be planned ahead and designed to best suit the defect. A major example is the use of the radial forearm free flap for oral reconstruction when compared to the pectoralis major flap (Jacobsen et al, 1995).

An interesting feature of free flaps is the possibility of reinnervation, with recovery of sensation at the defect area. Previous research demonstrated that nervous ingrowth may occur in noninnervated flaps (Sebesan et al, 2008), but this finding is controversial (Vries et al, 1996). In a case-control study comparing oral tongue resection patients after antebrachial cutaneous nerve-lingual nerve anastomosis and healthy controls, recovery of some sensory ability was demonstrated in all patients but significant differences were noted when compared to controls in mastication, speech intelligibility and sensory capabilities of the neotongue (Loewen et al, 2010).

The risk of recurrence is inherent to any malignant neoplasm and a significant proportion of oral cancer patients will present some form of it during their follow-up. Local recurrences may occur in 25 to $48 \%$ of patients with oral cavity or oropharynx squamous cell carcinomas, depending on their TNM stage and other pathological factors (Agra et al, 2006). When free flaps are used on the initial ablative procedure, the pectoralis major flap and other regional and local flaps are preserved for the eventuality of salvage surgery. This is a major advantage considering the impact of local tumor recurrence on patient performance and its capability to support a major procedure like microvascular flap surgery. The risk of a second primary head and neck cancer is also significant and may be another useful situation to have a local/regional flap available.

\subsection{Considerations on patient selection}

We consider all patients at their first ablative surgery as potential candidates for free flap reconstruction but, in a set of patients, we still perform local or regional flaps. The most significant decision criterion is the performance status of the patient (Rodrigues et al, 2009). 
Patients with a Karnofsky performance-status (KPS) below $60 \%$ aren't considered for free flap reconstruction. We also consider absence of suitable arterial recipient vessels in the neck as a major contraindication. The lack of venous recipient vessels is more easily managed by rotation of the cephalic vein or the use of interposition grafts. Finally, prior carotid surgery, as endarterectomy, is considered a contraindication for free flap transfer.

Importantly, age is not a contraindication to free flap surgery. The population's longevity is increasing worldwide and more and more patients get at the seventh decade of life and beyond in good overall health conditions. Also, the development of anesthetic techniques and intensive care support added to the security of performing major surgeries on these patients.

Nao et al analyzed the results of free flap reconstruction for elderly patients ( $>70 \mathrm{yrs})$ and showed that advanced patient age had a significant impact on overall, disease-free, and specific survival on univariate analysis but on multivariate analysis, only overall survival was affected. Most importantly, the functional outcomes were similar between old and young patients (Nao et al., 2011). In an article investigating the impact of age on patients submitted to major head and neck procedures, age wasn't considered as a major prognostic factor for surgical outcome (Boruk et al, 2005). In our own experience, age is no longer considered as significant when considering the reconstruction modality to be employed, being replaced by performance-status evaluation. This option is supported by several reports on the literature in which adequate control of preoperative comorbidity is performed (Bridger et al, 1994; Beausung et al, 2003).

In the salvage setting, free flaps are the first option for reconstruction. In this situation, patients usually have a lower KPS than at primary treatment and the possibility of vesseldepleted necks is higher. Therefore, we believe that reliability of the flap is a major concern with the radial forearm free flap and the anterolateral thigh flap being considered the first options due to their long and calibrous vascular pedicles. The need for vein grafting is more frequent in this setting. Finally, the major indication for free flap reconstruction in patients submitted to salvage is the functional improvement it may represent over conventional, pedicled flaps.

The surgeon must account for factors that may hinder tissue healing when planning the reconstruction. These factors are related both to patient and wound characteristics and may alter the healing progression and jeopardize patient recovery (table 1) (Pagedar \& Gilbert, 2009).

\begin{tabular}{ll}
\hline Patient-related factors & Wound-related factors \\
\hline & \\
Denutrition & Radiotherapy \\
Immunodeficiency & Contamination \\
Diabetes mellitus & Infection \\
Tobacco abuse & \\
Advanced age & \\
\hline
\end{tabular}

Table 1. Factors that may impact on healing in patients with oral cancer. 
An interesting point is made by Hanasono et al when comparing the impact of microsurgery on the outcomes of surgical oral cancer. They state that even after the availability of free flaps, a significant percentage of patients where still been reconstructed by regional or local pedicled flaps (Hanasono et al, 2009). We also believe that free flaps don't replace other modalities of reconstruction but should be considered as an addition to the options at disposal.

\section{Reconstruction of specific sites}

\subsection{Reconstruction of the oral cavity and oropharynx}

The upper aerodigestive tract is formed by multiple structures that possess complex and interdependent functions. They are essential for breathing and feeding as well as for the speech capabilities and their compromise may significantly impact on basic, survival capabilities as well as in personal communication. The resection of oral cancer implies in the interruption, at least temporarily, of these functions, adding morbidity to these patients. The reconstruction and rehabilitation phases of treatment aim at restoring function and self-image as similar as possible to those before treatment (Vos \& Burkey, 2004). The evolution of reconstructive surgery transformed the treatment of oral cancer from a highly disfigurative procedure, usually in multiple stages to a single stage procedure with adequate results. Nowadays, we cannot consider the treatment of the tumor as the final and unique objective to be pursued or be satisfied with quicker and easier reconstruction techniques if this will cause functional or cosmetic sequelae (Brennan \& Cummings, 1999).

A significant advantage of free flaps and the first step in the reconstruction is the choice of the donor area and the design and planning of the flap. It allows for tailor-made flaps designed to allow the preservation of the non-resected tissues' anatomy with improved function preservation and coverage of vessels and bone. A major example is the oral tongue in patients submitted to partial pelveglossectomies. Primary closure using a tongue flap will cause such decrease in mobility that the patient behaves like one submitted to total glossectomy. A fasciocutaneous microsurgical flap allows the preservation of tongue mobility along aside intraoral volume. This results in better functional results even for patients with small post-resection defects.

We standardized the following four flaps for reconstruction of the oral cavity and oropharynx: the radial forearm free flap (RFFF), the lateral arm flap (LAF), the rectus abdominis flap and the anterolateral thigh flap (ALTF). The choice among them depends on the extent of the defect, its location, the availability of recipient vessels and the patient body profile.

The main staples of oral tongue and oropharyngeal reconstruction are the LAF and the RFFF. They are chosen if the defect encompasses no more than $70 \%$ of the tongue. In these cases, a pliable, flexible and thin flap will allow adequate movements of the remaining tongue with good overall function.

The LAF has become our workhorse in patients that need a thin, pliable fasciocutaneous flap. Its main indications are (Faria el al, 2007): 
- Provide enough skin island for defect closure without tension;

- Primary closure of the donor area is possible;

- Good recipient vessels without the need for vein grafting;

- Compatible thickness of the flap with defect area;

The advantages of the LAF for oral reconstruction were also demonstrated in another article with assessment of donor site morbidity and esthetic outcome. The authors report an excellent esthetic outcome with a patient's satisfaction of 6.58 for the primary site and 7.13 for the donor area in a 0 to ten scale. They also remark that all patients had intelligible speech (Thankappan et al, 2011).

Otherwise, our second choice is the RFFF (Rodrigues et al, 2007). It possesses several disadvantages when compared to the lateral arm flap like the need to graft the donor area causing a cosmetic defect in an exposed area and the sacrifice of the radial artery. Its main indications in our routine are:

- $\quad$ Need of long, calibrous pedicle;

- Vein graft interposition in vessel depleted necks;

- Thickness more constant and predictable than LAF, which may be unsuitable in obese patients due to adipose tissue.

The anterolateral thigh flap may also be used for reconstruction of small defects in the oral cavity as demonstrated by Bussu et al. In a quality of life analysis, they found similar functional outcomes between the ALTF and other flaps after oral reconstruction, including the mobile tongue (Bussu et al, 2011). In a specific comparison of the ALTF and the RFFF for hemiglossectomy defects, both groups had similar functional outcomes regarding speech and swallowing. The donor area of the ALTF group were primarily closed without complications while the RFFF patients were all submitted to skin grafts with a $40 \%$ loss rate (de Vicente et al, 2008). Also, the ALTF donor area may provide more soft tissue, with a significant difference in flap area when compared to the RFFF $(p=0.005)$ at a lower complications rate $(p=0.035)$, the only significant disadvantage being the longer flap-harvesting time $(p=0.020)$ (Kesting et al, 2011). In an analysis of functional results after RFFF (17 patients) or ALTF (31 patients) for oral and oropharyngeal reconstruction, no significant differences could be demonstrated (Camaioni et al, 2008).

Patients that more than $70 \%$ of tongue removal are, in our opinion, better candidates for a bulky, thick flap that provides more intraoral volume and is less pliable. Resections involving the base of tongue has a significant impact on quality of life, especially in the oral feeding domain, and its restoration through free flap reconstruction seems to improve the effect of tissue loss (Hartl et al, 2009). Our choices in these cases are the anterolateral thigh flap and the rectus abdominis flap. The ALTF is usually preferred due to the large and long vascular pedicle and its flexible composition allowing transfer as a fasciocutaneous or a myocutaneous flap. In our experience, this flap had a significantly higher complication rate at the donor site than the RAFF but these most related to fluid accumulation and wound dehiscence with minimal impact on morbidity while the RAFF presented usually with more significant complications like bleeding and abdominal wall weakness. Also fasciocutaneous flaps pose less strain on the recipient vessels due to their lower blood flow. (Rodrigues et al, 
2006). A third option, no longer in routine use at our service, is the latissimus dorsi flap. Its indications were similar to those of the two previous flaps but the need to mobilize the patient during the procedure increased operative time and flap ischemia time. These bulky flaps allow for adequate oral intake and emission of a greater number of phonemes (in native Portuguese speakers) even after total removal of the tongue.

The planning of a bulky flap must consider its volume loss over time. In a recent article with serial volume evaluation by CT scan or magnetic resonance imaging, the estimated volume decrease was $20.9 \%$ and $24.8 \%$ for the ALTF at 12 and 24 months after the procedure (Cho et al, 2011). The use of adjuvant radiotherapy must also be remembered since it will have a major impact on fat tissue atrophy and therefore volume change (Fujioka et al, 2011). Another option for these patients is the gracilis myocutaneous flap. It allows for reinnervation with microsurgical anastomosis of the obturator nerve to the gracilis with the hypoglossus. This may preserve muscular tonus and decrease volume loss over time. The intention is to replace the motor function of the genioglossus muscle, that is significant for deglutition, and the mylohyoid muscle, that elevates the larynx and prevents aspiration (Yoleri \& Mavioglu, 2000).

A significant contribution for the rehabilitation of the oral cancer patient and its return to everyday life is made by the speech therapist. The first postoperative evaluation is performed immediately after patient dismissal from the intensive care unit and therapy is started as soon as possible. A major concern is to start oral feeding and remove the tracheostomy tube before the beginning of adjuvant therapy (radiotherapy or chemoradiation). We strongly believe that early rehabilitation will have a significant impact on late quality of life.

\subsection{Reconstruction of the mandible}

The resection of the mandible is an integral part of oral cancer treatment and may be caused by direct tumor invasion or to allow oncologic margins to be achieved. The mandible is essential for mastication, deglutition, speech and oral continence. Mandible reconstruction is therefore essential in obtaining adequate functional recovery and aims at preserving facial contour and better rehabilitation of both speech and oral feeding. Resections affecting the anterior arch are most prone to produce significant sequelae. Another significant factor when considering mandible reconstruction is future dental rehabilitation.

Free flaps were a major revolution for mandible reconstruction allowing long segments of vascularized bone to be used. They are more resistant to radiotherapy than bone grafts and present little resorption. Also, they allow for immediate dental rehabilitation using osteointegrated implants. Four flaps are commonly used for mandible reconstruction: the fibular flap, the iliac crest flap, the scapular flap and the radium flap. We will briefly discuss the first two since they are our usual choices.

The fibular osteocutaneous flap represents our first option for mandible reconstruction. It allows for a long segment (up to 25 centimeters) of vascularized bone to be transferred to the head and neck region with minor morbidity to the donor site. We consider as major 
advantages of this flap its long and reliable vascular pedicle and its location far away from the oncologic surgery site allowing for a two-team approach. A major drawback is the limited amount of soft tissue available in the traditional flap design although a technique with simultaneous transfer of the soleus muscle is described, allowing its use to reconstruct soft tissue defects or improving neck contour by replacing the sternocleidomastoid muscle after its removal en bloc with the neck dissection specimen (Ersoy et al, 2011). In our experience, we prefer a second flap when the fibular flap can't satisfy the need for soft tissue. In these patients we use either the pectoralis major myocutaneous flap or the microvascular ALTF. This finding is also demonstrated in he literature. In a review of patients with multiple free flap reconstructions at M.D. Cancer Center from 2001 to 2007, thirty-four patients (87 \%) had defects involving the mandible associated with extensive soft tissue resections. The reconstruction had a satisfactory functional result in most patients (Hanasono et al, 2008). The use of double simultaneous free flaps should be performed in selected patients due to the high complication rate of the procedure and usually limited functional outcome (Andrades et al, 2009). We prefer to reserve this reconstruction option in patients with low comorbidity index and good oncologic prognosis.

In a series of 117 patients submitted to free fibular flaps, the quantity of available bone, the height of the bone at reconstruction site, and the possibility of dental rehabilitation are the major advantages of the fibular flap. They point to a $8.5 \%$ failure rate and calf paresthesias as a major donor site morbidity, affecting 21 \% of patients (López-Arcas et al, 2010).

The iliac crest flap main indication is actually a contraindication to the fibular flap. Patients with previous history of lower limb fracture or signs of arterial vascular insufficiency are considered unsuitable for the fibular flap. Also, we perform this flap in patients with limited bone defect when the split iliac crest will suffice.

Although not in our routine use, the scapular flap is a good option when we consider the amount of soft tissue that may be taken along the bone flap. Its most significant feature is the possibility of two separate skin paddles, allowing for greater flexibility in flap suturing at the defect area. The osteocutaneous radial forearm free flap is presented as an alternative to the fibular flap. In a comparison, this flap presented a lower but not statistically significant $(\mathrm{p}=0.13)$ complication rate at the donor site and comparable rates of oral diet intake $(\mathrm{p}=0.49)$, bony malunion $(\mathrm{p}=0.26)$ and dental implants, although they were at a very low rate $(2.3 \%$ of all patients). Also, only patients with segmental mandible defects were included (Virgin et al, 2010).

\section{Oncologic results}

The reconstruction is usually implied in the functional results of the treatment although recently authors have investigated its role in the oncologic outcomes of oral cancer treatment. Series of patients submitted to free flap reconstruction focused on showing their survival results without effectively comparing different treatment modalities. The main focus was stating the acceptable survival rates obtained by free flap reconstruction and encouraging their use (Podrecca et al, 2006). These articles presented contradictory results due to different settings, patient selection and statistical analysis. 
In our opinion, a major impact of free flaps on the ablative procedure is the amount of tissue available for transfer. The oncologic surgeon has more freedom to extend the surgery beyond the limits of what could be safely reconstructed using the pectoralis major flap or local flaps. Also, the level of specialization necessary for microsurgery requires, usually, a two-team approach. This allows each team to focus on a single part of the procedure with greater freedom of action.

In a retrospective cohort of 98 patients submitted to either free flap or regional flap reconstruction, a significant difference in survival was noted between the two groups (67.3\% or free flaps and $47 \%$ for pedicled flaps, $p=0.03)$. In univariate analysis, compromised surgical margins and recurrence were significant for survival in the free flap group. At final analysis, the modality of reconstruction was not significant but showed a trend toward better survival (de Vicente et al, 2011). The impact of free flap was more evident in a retrospective study of 773 patients with oral squamous cell carcinoma. A direct comparison between the groups and a matched-pair were performed. In the first analysis, a significant impact of microsurgical reconstruction was observed (HR: $0.66,95 \%$ CI: $0.52-0.83, p<0.001)$ that was magnified by the matched-pair analysis (HR: $0.58,95 \%$ CI: $0.44-0.73, \mathrm{p}<0.001)$. The benefit of microsurgical reconstruction in these patients was observed mostly for patients with primary tumors staged as T3/T4a (HR: 0.46, 95\% CI: $0.31-0.69, \mathrm{p}<0.001)$ and the benefit for patients with $\mathrm{T} 1 / \mathrm{T} 2$ tumors was less clear although a trend towards better results was shown (HR: $0.74,95 \% \mathrm{CI}: 0.53-1.04, \mathrm{p}=0.08$ ). A significant characteristic from this article is that patients with close or compromised surgical margins were excluded from analysis. The authors consider free flap reconstruction recommended, especially when postoperative functional deficits are expected (Mücke et al, 2010). A small study also designed to evaluate the impact of microsurgical reconstruction on survival didn't show any significant improvement only a trend towards better prognosis (Marchetti et al, 2008). This study didn't directly compare the results of free flaps and pectoralis major pedicled flaps.

In a series from M.D. Anderson, the authors show the possible impact of free flap reconstruction on patient survival. They don't direct compare the impact of free flap reconstruction with pedicled flaps but rather of those patients operated before and after the establishment of microsurgical reconstruction. They report a higher rate of advanced tumors both at the primary site and in the neck after the availability of free flaps. In this series, free flaps didn't have a significant impact on local recurrence $(p=0.48)$, overall survival $(p=0.63)$ and disease-specific survival ( $\mathrm{pp}=0.124)$, but caused a significant decrease in compromised surgical margins rate. A major observation is that even after free flap introduction, approximately one-third of all patients receive pedicled flap reconstruction (Hanasono et al, 2009).

In a retrospective analysis of our experience including 605 patients (Rodrigues et al, 2011) we could confirm the two above-mentioned facts. After their introduction, free flaps became the main modality for reconstruction after oral cancer ablation (figure 1). A significant impact of free flaps occurred on the rate of compromised surgical margins $(p<0.0001)$. This increase in free margins rate in surgery had a significant impact on local recurrence rate (figure 2) and disease-specific survival (figure 3). Microvascular flaps also had a significant impact on the interval for adjuvant treatment, allowing its timelier introduction $(\mathrm{p}=0.03)$. 


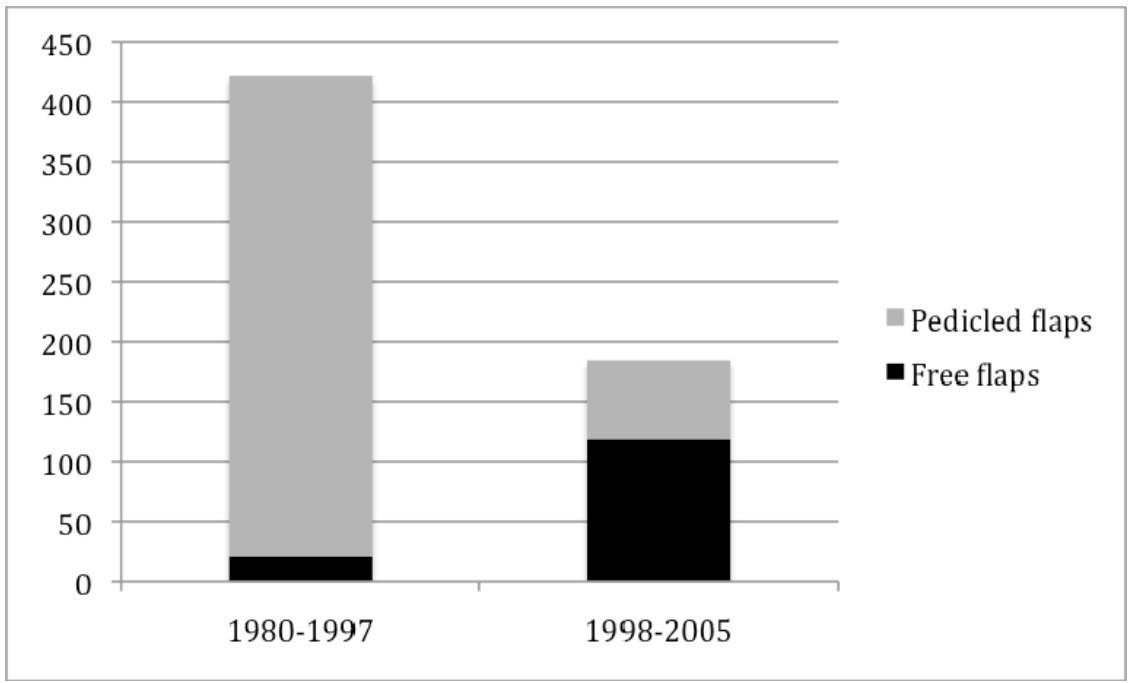

Fig. 1. Time period distribution of free and pedicled flaps in A C Camargo Hospital, São Paulo, Brazil.

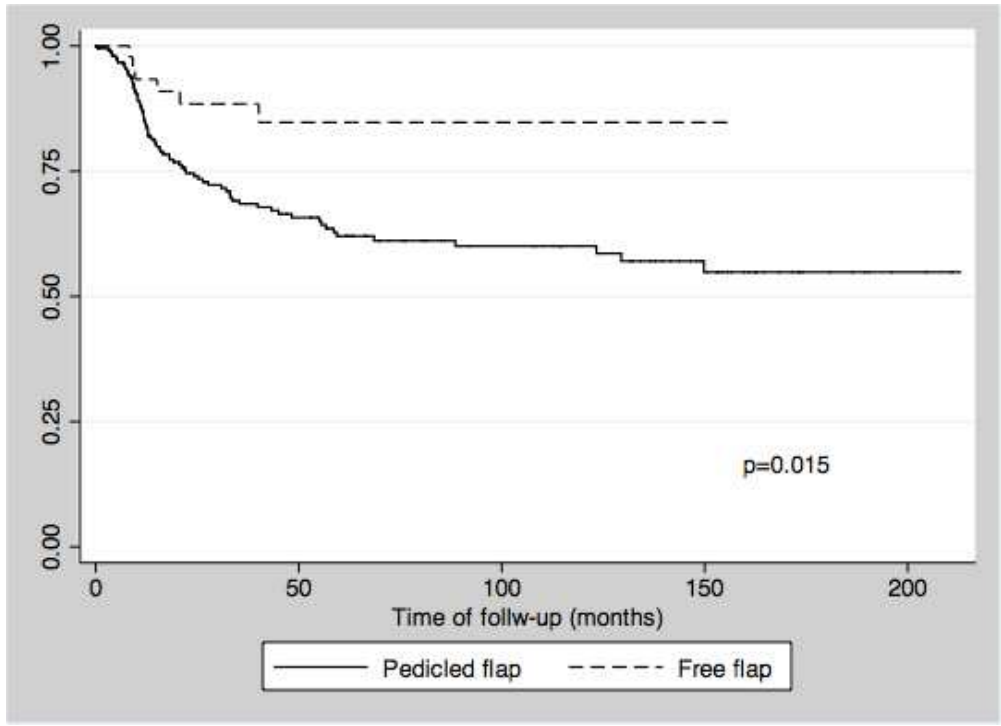

Fig. 2. Local recurrence in patients with advanced-stage (T3/T4) primary tumors submitted to pedicled or free flaps. 


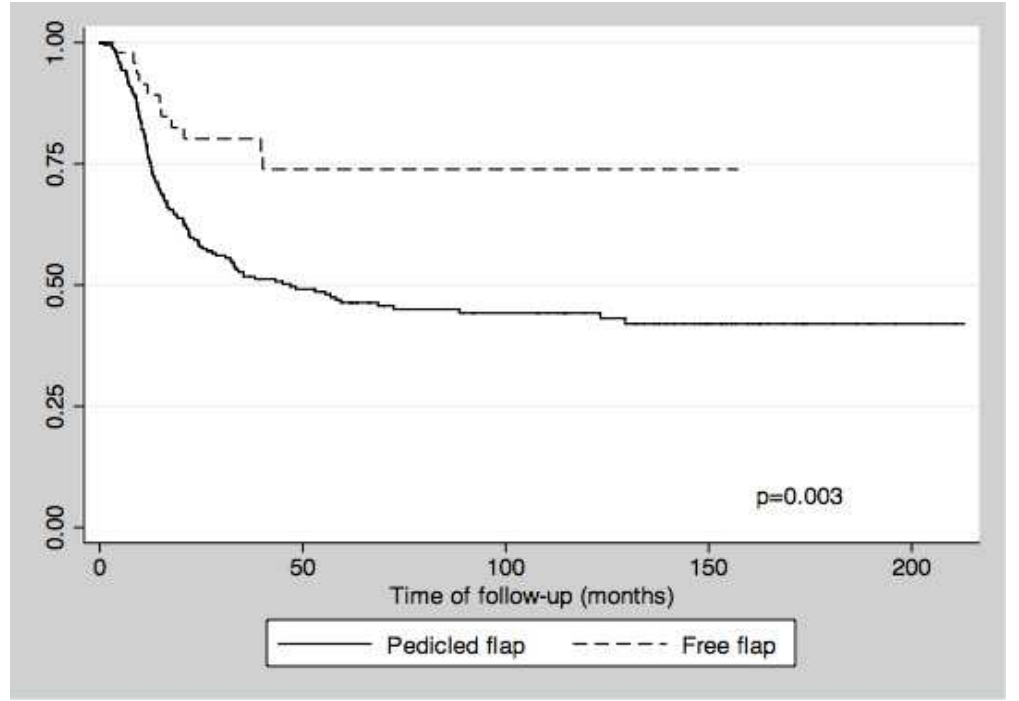

Fig. 3. Disease-specific survival in oral cancer patients according to reconstruction modality. Only patients with T3/T4 primary tumors were included.

Based on data from these different studies, we believe that oral cancer reconstructive surgery should be based on a two-team approach and make extensive use of free flaps. Its indication for patients with high-risk tumors has been challenged by cost-effectiveness analysis of these patients and their risk of recurrence. Some even argue that free flaps should be reserved for selected patients, excluding patients with features like advanced tumor stage, clinically compromised neck lymph nodes and other poor prognosis markers. These patients would derive the least benefit from the reconstructive procedure (Schusterman et al, 1991). Our opinion is exactly the opposite. All patients with oral cancer should be considered candidates for free flap reconstruction and adverse prognostic characteristics shouldn't be considered a counter indication. Usually, these patients are those that have extensive soft tissue or mandible defects and whose rehabilitation will be significantly improved by free flaps. As demonstrated by our experience (Rodrigues et al, 2011) and the article by Mücke et al (Mücke et al, 2010), the choice of reconstruction modality may even have a significant impact on their oncologic outcome. Although the three studies that compare he impact of microsurgical flaps on survival have different inclusion criteria, the sum of their results in a meta-analysis, favors the use of free flaps over pedicled flaps in oral cancer patients (table 2).

\begin{tabular}{llll}
\hline Study & RR & $95 \%$ CI & Weight \\
\hline & & & \\
de Vicente, 2011 & 1.139 & $0.898-1.445$ & 7.54 \\
Rodrigues, 2011 & 1.233 & $1.137-1.336$ & 37.31 \\
Mücke, 2010 & 1.087 & $1.004-1.177$ & 55.15 \\
Pooled RR & 1.145 & $1.083-1.211$ & 100.00 \\
\hline
\end{tabular}

Table 2. Meta-analysis of the oncologic outcome of free flaps reconstruction on oral cancer patients. 


\section{Functional outcomes}

Good functional outcomes are a major objective of head and neck reconstructive surgery. They mean not only quality of life but also survival. In a previously published study, good general physical health, ability to oral feed communication and absence of pain were strongly correlated with survival (Karvonen-Gutierrez et al, 2008). The return to preoperative status is the ultimate goal, allowing resumption of a normal, productive life with adequate social interaction and quality of life.

In a prospective study of quality of life using the University of Washington - Quality of life and the Head and Neck Performance Status Scale a significant impact of the reconstruction modality is observed. A significant decrease of the scores is observed after 3 months, with progressive improvement until 1 year after treatment, achieving normal or near normal function in $77 \%$ of patients. In multivariate analysis, segmental mandibulectomy and free flap reconstruction were significant, with significant improvement when compared to other reconstruction modalities (Villaret et al, 2008). This finding is confirmed by another study that evaluates quality of life before and after surgery and free flap reconstruction of advanced stage head and neck cancer. A significant decrease is observed immediately after treatment with significant improvement and return to preoperative levels after six months (Rizvi et al, 2009).

The removal of the mobile tongue is perhaps the main cause of disability and functional limitation after oral cancer ablation. The use of the RFFF may significantly improve the outcome of such patients. Longitudinal analysis of swallowing function and tongue mobility in a group of 15 patients and comparison against patients without tongue involvement shows a significant decrease in liquid swallowing and posterior tongue motility after one month of treatment. But all measures returned to baseline level after 12 months, indicating a good capacity of functional recovery over time. The role of post-treatment rehabilitation through a multi-specialty team is specially indicated as it provides the best results (Brown et al, 2010). In an analysis of patients submitted to oral cancer ablation and RFFF reconstruction, high comorbidity index, large flap surface, radiotherapy and involvement of the mobile tongue were significant for poorer functional outcomes. Despite this, $87 \%$ were on exclusive oral diet and $80 \%$ had intelligible speech (Bozec et al, 2009). The RFFF may be transferred as an innervated flap. In this case, limited recovery of sensorial function is possible, although not full recovery.

Videofluoroscopy (VF) has been used for assessment of deglutition after free flap reconstruction for oral cancer in 20 patients. It demonstrated an $89.4 \%$ of good neotongue mobility with adequate control of he food bolus in $73.6 \%$ of patients. In $85 \%$ of patients, oral diet could be resumed and $75 \%$ had intelligible speech and were able to effectively communicate. It is concluded that free flaps significantly improve life quality with adequate rehabilitation of swallowing and speech capabilities (Archontaki et al, 2010). VF evaluation in patients submitted to base of tongue resection and RFFF reconstruction also show a good functional recovery. In a prospective series of 20 consecutive patients, nineteen were able to resume oral feeding with good swallowing function without signs of aspiration. The flap allows for good apposition of the base of tongue and posterior pharyngeal wall preserving deglutition mechanics ( $\mathrm{O}^{\prime}$ Connell et al, 2008). Using a barium swallow in a series of 100 consecutive patients, tongue base resection and preoperative radiotherapy were the only 
significant factors for post-treatment aspiration in patients submitted to microsurgical flap reconstruction (Smith et al, 2008). The evaluation of our results in patients submitted to retromolar or oropharyngeal tumor ablation and reconstruction showed a significant improvement of deglutition among those submitted to free flaps with a compromise of both oral and pharyngeal phases in the pectoralis major flap group. No significant difference in aspiration rate was demonstrated between the two groups (Bandeira et al, 2007).

In a direct comparison of swallowing function among patients submitted to free or pedicled flaps, the type of reconstruction had no significant impact on resumption of oral feeding. The significant factor for functional swallowing was defect location, with lateral defects having a significant better prognosis than central defects (Schache et al, 2009). When is the focus is shifted to speech, a direct comparison of the RFFF and the pectoralis major pedicled flap show a distinctive advantage of the free flap. Also, intraoral dehiscence rate for the pectoralis major flap was significantly higher than that of the RFFF ( $\mathrm{O}^{\prime} \mathrm{Neill}$ et al, 2010).

In a cross-sectional study, a direct comparison between chemoradiation and primary surgery with microsurgical flap reconstruction was performed. The study included 49 patients and they used UoW - QoL modules c30+hn35 to compare the functional outcomes between the two groups. The majority of ICF categories failed to demonstrate any significant difference between the two groups but a trend toward better overall life quality was suggested in the surgical group (Tshierner et al, 2011). This article demonstrates that operative and non-operative management of oral cancer patients have similar functional outcomes.

When compared to the pectoralis major pedicled flap, the free flap possesses a major advantage in functional outcomes also outside the swallowing and speech domains. In a retrospective review of 100 patients among 491 eligible, speeds, shoulder function and mood were significantly better in patients submitted to free flaps (Hsing et al, 2011). The use of free flaps after salvage surgery in patients originally treated by radiotherapy or chemoradiation has significant worse functional outcomes than after initial surgery followed by adjuvant treatment. In a series of 72 patients, most patients (56\%) required enteral tube feeding on a definitive basis (Kostrzewa et al, 2010).

\section{Risk factors and complications of free flap oral reconstruction}

Patients submitted to free flap reconstruction might present in the post-operative period complications related to the ablative procedure, the reconstruction and its clinical conditions. Our major objective here is to discuss the complications related to the flap itself. In a review of 150 patients, female gender and operative time longer than 10 hours were significant predictors of major surgical complications (Rosenberg et al, 2009). In an analysis of 796 consecutive patients, two hundred thirty-nine patients $(30 \%)$ had a complication demanding lengthening of hospital stay or reoperation. Smoking, ASA score, and low preoperative hemoglobin levels were significant predictors of perioperative morbidity and the two last ones also for surgical complications (Patel et al, 2010).

Infections are a major concern after microsurgical reconstruction. By definition, oral surgeries are contaminated and therefore are already at a higher infection risk. In an analyis of 276 patients submitted to free flap reconstruction, one hundred and twelve patients 
(40.6\%) had post-operative surgical-site infection. Duration of surgery and ASA (American Society of Anesthesiologists) score were significant factors for local and neck infection (Karakida et al, 2010). In our experience, surgical site infections were the most frequent postoperative complication, occurring in 94 patients (15.54\%). In two cases $(0.33 \%)$, patients presented with infection at the donor site.

Although controversial, previous radiotherapy with or without chemotherapy is implicated in wound complications after oral cancer surgery (Sassler et al, 1995). Remodeling of the extracellular matrix and expression of transforming growth factor beta (1) were significantly different in patients submitted to previous irradiation and this factor alone was significant for flap success or failure (Lee \& Thiele, 2010). In this setting, the transfer of healthy tissue with a reliable blood supply is of major significance for improving healing. The impact of radiotherapy on flap success rate seems to be negligible (Kruse et al, 2010). The addition of chemotherapy to radiotherapy in the adjuvant treatment doesn't have a significant impact on the success rate, with results comparable to that after radiotherapy alone (Kostrzewa et al, 2010).

In an analysis of 2372 free flaps for head and neck reonstruction, a major prognotic factor for flap loss was secondary reconstruction. The survival rate in primary reconstructions was $93.9 \%$ compared to only $88.7 \%$ in the secondary reconstruction setting $(p<0.05)$. Posible factors to explain this difference include higher infection rate, delayed wound healing and depleted vessel neck (Nakatusuka et al, 2003). Thrombosis of the vascular anastomosis, although rare, is a significant complication and may lead to flap loss. In a recent review of multiple centers in the Netherlands, no single protocol for pharmacological thrombosis prevention could be defined. The authors emphasize the role of preoperative smoke cessation and careful vascular handling during surgery with an individualized postoperative treatment based on risk profile (Brands et al, 2009).

\section{References}

Agra IMG, Carvalho AL, Ulbrich FS, Campos OD, Martins EP, Magrin J \& Kowalski LP. (2006). Prognostic factors in salvage surgery for recurrent oral and oropharyngeal cancer. Head Neck, Vol. 28, No. 2, (February 2006), pp. 107-113, ISSN 1043-3074.

Andrades P, Bohannon IA, Baranano CF, Wax MK \& Rosenthal E. (2009). Indications and outcomes of double free flaps in head and neck reconstruction. Microsurgery, Vol. 29, No. 3, (March 2009), pp. 171-177, ISSN 1098-2752.

Archontaki M, Athanasiou A, Stavrianos SD, Korkolis DP, Faratzis G, Papadopoulou F, Kokkalis G \& Rapidis AD. (2010). Functional results of speech and swallowing after oral microvascular free flap reconstruction. European Archives of Otolaryngology Head and Neck Surgery, Vol. 267, Nr. 11, (November 2010), pp. 1771-1777, ISSN 1434-4726

Ariyan S. (1979). The pectoralis major myocutaneous flap: a versatile flap for reconstruction in the head and neck. Plastic Reconstrutive Surgery, Vol. 63, No. 1, (January 1979), pp. 73-81, ISSN 0032-1052.

Ariyan S. (1979). Further experiences with the pectoralis major myocutaneous flap for the immediate repair defects from excisions of head and neck cancers. Plastic Reconstructive Surgery, Vol. 64, No. 5, (May 1979), pp. 605-612, ISSN 0032-1052. 
Bakamjian VY. (1965). A two-stage method for pharyngo-esophageal reconstruction with a primary pectoral skin flap. Plastic Reconstrutive Surgery, Vol. 36, No. , (August 1965), pp. 173-184, ISSN 0032-1052.

Bandeira AKC, Tomazelli MFGG, do Vale-Prodomo LP, Vartanian JG, Faria JCM, Rodrigues ML, Kowalski LP, Carrara-de Angelis E. (2007) Analysis of swallowing after retromolar or oropharynx resection and reconstruction with myocutaneous or microvascular free flaps. Applied Cancer Research, Vol 27, No. 1, (January 2007), pp. 23-29, ISSN 1980-5578

Beausung ES, Ang EE, Lipa JE, Irish JC, Brown DH, Gullane PJ, Neligan PC. (2003). Microvascular free tissue transfer in elderly patients: the Toronto experience. Head Neck, Vol. 25, No. 7, (July 2003), pp. 549-553, ISSN 1043-3074.

Boruk M, Chernobilsky B, Rosenfeld RM \& Har-El G. (2005). Age as a prognostic factor for complications of major head and neck surgery. Archives of Otolaryngology Head and Neck Surgery, Vol. 131, No. 7, (July 2005), pp. 605-609, ISSN 0886-4470.

Bozek A, Poissonnet G, Chamorey E, Laout C, Vallicioni J, Demard F, Peyrade F, Follana P, Bensadoun RJ, Benezery K, Tharial J, Marcy PY, Sudada A \& Dassonville O. (2009). Radical ablative surgery and radial forearm free flap ( RFFF) reconstruction for patients with oral and oropharyngeal cancer: postoperative outcomes and oncologic and functional results. Acta Otolaryngologica, Vol. 129, No. 6, (June 2009), pp. 681-687, ISSN 0001-6489.

Brands MT, van den Bosch SC, Dieleman FJ, Bergé SJ \& Merkx MA. (2009). Prevention of thrombosis after microvascular tissue transfer in the head and neck. A review of the literature and the state of affairs in Dutch Head and Neck Cancer Centers. International Journal of Oral and Maxillofacial Surgery, Vol. 39, No. 2, (February 2010), pp. 101-106, ISSN 0901-5027.

Brennan JA, Cummings CW. (1999). Controversy in the management of tumors of the oral cavity. In:. Comprehensive Management of Head and Neck Tumors. Thawley SE, Panje WR, Batsakis JG, Lindberg RD (editors), pgs 733-735. WB Saunders ISBN: 0-72165582-3, Philadelphia - USA.

Bridger AG, O'Brien CJ \& Lee KK. (1994). Advanced patient age should should not preclude the use of free-flap reconstruction for head and neck cancer. American Journal of Surgery, Vol. 168, No. 5, (November 1994), pp. 425-428, ISSN 0002-9610.

Brown L, Rieger JM, Harris J \& Seikaly H. (2010). A longitudinal study of functional outcomes after surgical resection and microvascular reconstruction for oral cancer: tongue mobility and swallowing function. Journal of Oral and Maxillofacial Surgery, Vol. 68, No. 11, (November 2010), pp. 2690-2700, ISSN 0901-5027

Bussu F, Salgarello M, Adesi LB, Rigante M, Parrilla C, Guidi ML, Paludetti G \& Almadori G. (2011). Oral cavity defect reconstruction using anterolateral thigh free flaps. BENT, Vol. 7, No. 1, (January 2011), pp. 19-25, ISSN 1781-782X

Camaioni A, Loreti A, Damiani V, Bellioni M, Passali FM \& Viti C. (2008). Anterolateral thigh cutaneous flap vs radial forearm free-falp in oral and oropharyngeal reconstruction: an analysis of 48 flaps. Acta Otorhinolaryngologica Italica, Vol. 28, No. 1, (February 2008), pp. 7-12, ISSN 0392-100X.

Cho KJ, Joo YH, Sun DI \& Kim MS. (2011). Perioperative clinical factors affecting volume changes of reconstructed flaps in head and neck cancer patients: free versus 
regional flaps. European Archives of Otolaryngology Head and Neck Surgery, Vol. 268, No. 7, (July 2011), pp. 1061-1065, ISSN 1434-4726.

de Vicente JC, de Villalaín L, Torre A \& Peña I. (2008). Microvascular free tissue transfer for tongue reconstruction after hemiglossectomy: a functional assessment of radial forearm versus anterolateral thigh flap. Journal of Oral and Maxillofacial Surgery, Vol 66, No. 11, (November 2008), pp. 2270-2275, ISSN 0901-5027.

de Vicente JC, Rodríguez-Santamarta T, Rosado P, Peña I, de Villalaín L. Survival after free flap reconstruction in patients with advanced oral squamous cell carcinoma. Journal of Oral and Maxillofacial Surgery 2011 Jun 17 [Epub ahead of print] DOI 10.1016/j.joms.2011.02.202, ISSN 0901-5027.

Ersoy B, Sönnez A \& Bayramiçli M. (2011) Sternocleidomastoid region restoration with lateral hemisoleus incorporated in free fibular flap for reconstruction of radical neck dissection and hemimandibulectomy. Microsurgery Vol. 31, No. 5, (May 2011), pp. 401-403, ISSN 1098-2752.

Faria JCM, Scopel GP, Rodrigues ML, Kowalski LP, Ferreira MC. (2007). The versatility of the free lateral arm flap in head and neck soft tisue reconstruction: analysis of 210 cases. Journal of Plastic, Reconstructive and Aesthetic Surgery, Vol. 61, No. 2, (February 2007), pp. 172-179, ISSN 1748-6815.

Fujioka M, Masuda K, Imamura Y. Fattys tissue atrophy if free flap used for head and neck reconstruction. Microsurgery Vol. 31, No. 1, (January 2011), pp. 32-35, ISSN 10982752 .

Gal TJ \& Futran ND. (2002). Outcomes research in head and neck reconstruction. Facial Plastic Surgery 2002, Vol. 18, No. 2, (April 2002), pp. 113-7, ISSN 0736-6825.

Hanasono MM, Weinstock YE \& Yu P (2008). Reconstruction of extensive head and neck defects with multiple simultaneous free flaps. Plastic Reconstructive Surgery, Vol. 122, No. 6, (December 2008), pp. 1739-1746, ISSN 0032-1052.

Hanasono MM, Friel, MT, Klem C, Hsu PW, Robb GL, Weber RS, Roberts DB \& Chang DW. (2009). Impact of reconstructive microsurgery in patients with advanced oral cavity cancers. Head Neck, Vol. 31, No. 10, (October 2009), pp. 1289-1296, ISSN 1043-3074.

Hartl DM, Dauchy S, Escande C, Bretagne E, Janot F \& Kolb F. (2009). Quality of life after free-flap tongue reconstruction. Journal of Laryngology and Otology, Vol. 123, No. 5, (May 2009), pp. 550-554, ISSN 0022-2151.

Hsing CY, Wong YK, Wang CP, Wang CC, Jiang RS, Chen FJ, Liu SA. (2011). Comparison between free flap and pectoralis major pedicled flap for reconstruction in oral cavity cancer patients -- quality of life analysis. Oral Oncology Vol. 47, No. 6, (June 2011), pp. 522-527, ISSN 1368-8375.

Jacobson MC, Franssen E, Fliss DM, Birt D \& Gilbert RW. (1995). Free forearm flap in oral reconstruction. Archives of Otolaryngology Head and Neck Surgery, Vol. 121, No. 9, (Steptember 1995), pp. 959-964, ISSN 0886-4470.

Karakida K, Aoki T, Ota Y, Yamaaki H, Otsuru M, Takahashi M, Sakamoto H \& Miyasaka M. (2010). Analysis of risk factors for surgical-site infections in 276 oral cancer surgeries with microvascular free-flap reconstructions at a single university hospital. Journal of Infection and Chemotherapy, Vol. 16, No. 5, (October 2010), pp. 334-339, ISSN 1341-321X. 
Karvonen-Gutierrez CA, Ronis DL, Fowler KE, Terrell JE, Gruber SB \& Duffy SA. Quality of life scores predict survival among patients with head and neck cancer. Journal of Clinical Oncology 2008; 26, No. 16, (June 1, 2008), pp. 2754-2760, ISSN 0732-183X.

Kesting MR, Hölzle F, Wales C, Steinstraesser L, Wagenpfeil S, Mücke T, Rohleder NH, Wolff KD, Haler RJ. (2011). Microsurgical reconstruction of the oral cavity with free flaps from the anterolateral thigh and the radial forearm: a comparison of perioperative data from 161 cases. Annals of Surgical Oncology, Vol. 18, No. 7, pp. 1988-1994, (July 2011), ISSN 1068-9265.

Kostrzewa JP, Lancaster WP, Iseli TA, Desmond RA, Carroll WR \& Rosenthal EL. Outcomes of salvage surgery with free flap reconstruction for recurrent oral and oropharyngeal cancer. Laryngoscope 2010; 120, No. 2, (February 2010): 267-272, ISSN 1531-4995.

Kruse AL, Luebbers HT, Grätz KW, Obwegeser JA. (2010). Factors influencing survival of free-flap in reconstruction for cancer of the head and neck: a literature review. Mirosurgery Vol. 30, No. 3, (March 2010), pp. 242=248, ISSN 1098-2752.

Lee $S$ \& Thiele $C$. factors associated with free flap complications after head and neck reconstruction and the molecular basis of fibrotic tissue rearrangement in preirradiated soft tissue. Journal of Oral and Maxillofacial Surgery, Vol. 68, No. 9, (September 2010), pp. 2169-2178, ISSN 1531-5053.

Loewen IJ, Boliek CA, Harris J, Seikaly H \& Rieger JM. (2010). Oral sensation and function: a comparison of patients with innervated radial forearm free flap reconstruction to healthy matched individuals. Head Neck, Vol. 32, No. 1, (January 2010), pp. 85-95, ISSN 1043-3074.

López-Arcas JM, Arias J, Del Castillo JL, Burgueño M, Navarro I, Móran MJ, Chamorro M \& Martorelli V. The fibula osteomyocutaneous flap for mandible reconstruction: a 15year experience. Journal of Oral and Maxillofacial Surgery 2010; Vol. 68, No. 10, (Ocotber 2010), pp. 2377-2384, ISSN 0278-2391.

Marchetti C, Pizzigallo A, Cipriani R, Campobassi A \& Badiali G. Does microvascular free flap reconstruction in oral squamous cell carcinoma improve patient survival? Otolaryngology - Head and Neck Surg 2008; 139 (6), (June 2008), pp. 775-780, ISSN 0194-5998.

McGregor IA. The temporal flap in intra-oral cancer: its uses in repairing the post-excisional defect. British Journal of Plastic Surgery 1963; 16: 10, (October 1963), pp. 318-335, ISSN 0007-1226.

Mücke T, Wolff KD, Wagenpfeil S, Mitchell DA \& Hölzle. F. Immediate microsurgical reconstruction after tumor ablation predicts survival among patients with head and neck carcinoma. Annals of Surgical Oncology 2010; 17, No. 1, (January 2010), 287-295, ISSN 1068-9265.

Nakatsuka T, Harii K, Asato H, Takushima A, Ebihara S, Kimata Y, Yamada A, Ueda K \& Ichioka S. Analytic review of 2372 fre flap transfers for head and neck reconstruction following cancer resection. Journal of Reconstructive Microsurgery 2003; 19, No. 6, pp. 363-368, ISSN 0743-684X.

O,Brien BM, Morrison WA, Ishida H, MacLeod AM \& Gilbert A. (1974). Free flap transfers with microvascular anastomoses. British Journal of Plastic Surgery, Vol. 27, No. 3, (July 1974), pp. 220-230, ISSN 0007-1226. 
O'Connell DA, Rieger J, Harris JR, Dziegielewski P, Zalmanowitz J, Sytsanko A, Li S, Wolfaart J, Hart RD \& Seikaly H. Swallowing function in patients with base of tongue cancers treated with primary surgery and reconstructed with a modified radial forearm free flap. Archives of Otolaryngology - Head and Neck Surgery 2008; 134, No. 8, (August 2008), pp. 857-864, ISSN 0886-4470.

O'Neill JP, Shine N, Eadie PA, Beausang E, \&Timon C. (2010). Free tissue transfer versus pedicled flap reconstruction of head and neck malignancy defects. Irish Journal of Medical Sciences, Vol. 179, No. 3, (September 2010), pp. 337-343, ISSN 0021-1265.

Pagedar, NA \& Gilbert, RW. (2009). Principles of head and neck reconstruction. In: Principles and practice of head and neck surgery and oncology. Montgonomery PQ, Evans PHR \& Gullane PJ. (editors). Informa UK, pp. 527-540, England.

Patel RS, McCluskey SA, Goldstein DP, Minkovich L, Irish JC, Brown DH, Gullane PJ, Lipa JE \& Gilbert RW. (2010). Clinicopathologic and thrapeutic risk factors for perioperative complications and prolonged hospital stay in free flap reconstruction of the head and neck. Head Neck, Vol. 32, No. , pp. 1345-1353, ISSN 1043-3074.

Podrecca S, Salvatori P, Squadrelli Saraceno M, Fallahdar D, Calabrese L, Cantù G \& Molinari R. (2006) Review of 346 patients with free-flap reconstruction following head and neck surgery for neoplasm. Journal of Plastic, Reconstructive and Aesthetic Surgery, Vol. 59, No. 2, (February 2006), pp.122-129, ISSN 1748-6815..

Rizvi TA, Rashid M, Ahmed B, Haq EU, Sarwar SU, Zia-ul-Islam M \& Tamimy MS. (2009). Quality of life assessment in patients with locally advanced head and neck malignancy after ablative surgery and reconstruction with microvascular free flaps. Journal of the College of Physicians and Surgeons - Pakistan, Vol. 19, No. 2, (February 2009), pp. 108-112, ISSN 1681-7168.

Rodrigues ML, Faria JCM, Köhler HF, Kowalski LP. Retalhos ântero-lateral da coxa e reto abdominal em grandes reconstruções tridimensionais em cabeça e pescoço. (2006). Revista Brasileira de Cirurgia de Cabeça e Pescoço, Vol. 35, No. 4, (October 2006), pp. 244-248, (2006) ISSN 0100-2171

Rodrigues ML, Faria JCM, Kohler HF, Kowalski LP. Comparação entre os rtalhos microcirúrgicos antebraquial e lateral do braço em reconstruções de boca e orofaringe. (2007). Revista Brasileira de Cirurgia de cabeça e Pescoço, Vol. 36, No. 2, (Abril 2007), pp. 126-129 (). ISSN 0100-2171.

Rodrigues ML, Köhler HF, Magrin J, Bressan A, Faria JCMF \& Kowalski LP. (2011). Which oral cancer patients benefit the most from microsurgical reconstruction? European Journal of Plastic Surgery 2011;, Vol. 34, No. 2, (April 2011), pp. 75-80, ISSN 0930$343 X$.

Rodrigues ML, Köhler HF, Faria JCM, Ikeda MK, Vartanian JG \& Kowalski LP. (20090. Reconstruction after extended orbital exanteration using a fronto-lateral flap. International Journal of Oral and Maxillofacial Surgery 2009; Vol. 38, No. 8, (August 2009), pp. 850-854, ISSN 0901-5027.

Rosenberg AJ, van Cann EM, van der Bilt A, Koole R \& van ES RJ. (2009). A prospective study on prognostic factors for free-flap reconstructions of head and neck defects. International Journal of Oral and Maxillofacial Surgery, Vol. 38, No. 6, (June 2009), pp. 666-670, ISSN 0901-5027. 
Sassler AM, Esclamado RM \& Wolf GT. (1995). Surgery after organ preservation therapy. Analysis of wound complications. Archives of Otolaryngology Head and Neck Surgery, Vol. 121, No. 2, (February 1995), pp. 162-165, ISSN 0886-4470.

Schache AG, Lieger O, Rogers P, Kelly A, Newman L \& Kalavrezos N. (2009). Predictors of swallowing outcome in patients treated with surgery and radiotherapy for advanced oral and oropharyngeal cancer. Oral Oncology, Vol. 45, No. 9, (Setember 2009), pp. 803-808, ISSN: 1368-8375.

Sabesan T, Ramchandani PL \& Ilankovan V. (2008) Sensory recovery in noninnevated free flap in oral and oropharyngeal reconstruction. International Journal of Oral and Maxillofacial Surgery, Vol. 37, No. 9, (September 2008), pp. 819-823, ISSN 0901-5027.

Seidenberg B, Rosenak S, Hurwitt ES \& Som ML. (1959). Immediate reconstruction of the cervical esophagus by a revascularized isolated jejunal segment. Annals of Surgery, Vol. 149, No. 2, (February 1959), pp. 162-171, ISSN 0148-7043.

Smith JE, Suh JD, Erman A, Nabili V, Chhetri DK \& Blackwell KE. (2008) Risk factors predicting aspiration after free flap reconstruction of oral cavity and oropharyngeal defects. Archives of Otolaryngology - Head and Neck Surgery 2008; 134, No. 11, (November 2008), pp. 1205-1208, ISSN 0886-4470.

Thankapaan K, Kuriakose MA, Chatni SS, Sharan R, Trivedi NP, Vijayaraghavan S, Sharma M \& Iyer S. (2011) Lateral arm flap for oral tongue reconstruction: an analysis of surgical details, morbidity, and functional and aesthetic outcome. Annals of Plastic Surgery, Vol. 66, No. 3, (March 2011), pp. 261-266, ISSN 0148-7043.

Villaret AB, Cappiello J, Piazza C, Pedruzzi B \& Nicolai P. (2008) Quality of life in patients treated for cancer of the oral cavity requiring reconstruction: a prospective study. Acta Otorhinolaryngologica Italica, Vol. 28, No. 3, (June 2008), pp. 120-125, ISSN 0392100X.

Virgin FW, Iseli TA, Iseli CE, Sunde J, Carroll WR, Manuson JS \& Rosenthal EL. (2010) Functional outcomes of fibula and osteocutaneous forearm free flap reconstruction for segmental mandibular defects. Laryngoscope, Vol. 120, No. 4, (April 2010), pp. 663-7, ISSN 0023-852X

Vos JD \&Burkey BB. (2004) Functional outcomes after free flap reconstruction of the upper aerodigestive tract. Current Opinion in Otolaryngology Head and Neck Surgery, Vol.12, No. 4, (August 2004), pp. 305-310, ISSN 1068-9508.

Vries JPM, Acosta R, Soutar DS \& Webster MHC. (1996) Recovery of sensation in the radial forearm free flap in oral reconstruction. Plastic Reconstructive Surgery, Vol 98, No. 4, (September 1996), pp. 649-656, ISSN 0032-1052.

Yoleri L, Mavioglu H. (2000) Total tongue reconstruction with free functional gracilis muscle transplantation: a technical note and review of the literature. Annals of Plastic Surgery, Vol. 45, No. 2, (August 2000), pp. 181-186, ISSN 0148-7043. 


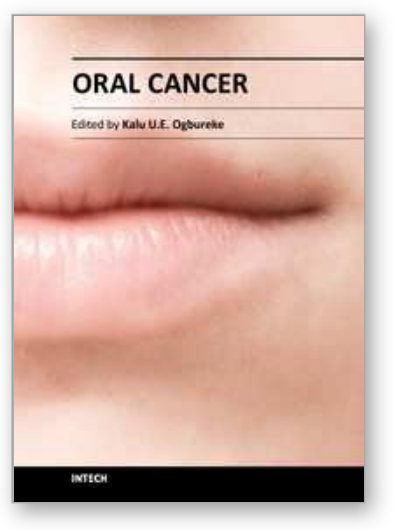

\author{
Oral Cancer \\ Edited by Dr. Kalu U. E. Ogbureke
}

ISBN 978-953-51-0228-1

Hard cover, 388 pages

Publisher InTech

Published online 14, March, 2012

Published in print edition March, 2012

Oral cancer is a significant public health challenge globally. Although the oral cavity is easily accessible, early diagnosis remains slow compared to the enhanced detection of cancers of the breast, colon, prostate, and melanoma. As a result, the mortality rate from oral cancer for the past four decades has remained high at over $50 \%$ in spite of advances in treatment modalities. This contrasts with considerable decrease in mortality rates for cancers of the breast, colon, prostate, and melanoma during the same period. This book attempts to provide a reference-friendly update on the etiologic/risk factors, current clinical diagnostic tools, management philosophies, molecular biomarkers, and progression indicators of oral cancer.

\title{
How to reference
}

In order to correctly reference this scholarly work, feel free to copy and paste the following:

Mônica Lúcia Rodrigues, Hugo Fontan Köhler and Luiz Paulo Kowalski (2012). Microsurgical Reconstruction of the Oral Cavity and Oropharynx After Cancer Ablation, Oral Cancer, Dr. Kalu U. E. Ogbureke (Ed.), ISBN: 978953-51-0228-1, InTech, Available from: http://www.intechopen.com/books/oral-cancer/microsurgicalreconstruction-of-the-oral-cavity-and-oropharynx-after-cancer-ablation

\section{INTECH}

open science | open minds

\section{InTech Europe}

University Campus STeP Ri Slavka Krautzeka 83/A 51000 Rijeka, Croatia Phone: +385 (51) 770447

Fax: +385 (51) 686166 www.intechopen.com

\section{InTech China}

Unit 405, Office Block, Hotel Equatorial Shanghai No.65, Yan An Road (West), Shanghai, 200040, China 中国上海市延安西路65号上海国际贵都大饭店办公楼 405 单元 Phone: +86-21-62489820

Fax: +86-21-62489821 
(C) 2012 The Author(s). Licensee IntechOpen. This is an open access article distributed under the terms of the Creative Commons Attribution 3.0 License, which permits unrestricted use, distribution, and reproduction in any medium, provided the original work is properly cited. 